\title{
Using real-time syndromic surveillance to monitor the health effects of air pollution
}

\author{
Sally Harcourt ${ }^{\star 1}$ Lydia Izon-Cooper², Felipe D. Colón-González³, Roger Morbey ${ }^{1,4}$, \\ Gillian Smith ${ }^{1,4}$, Naima Bradley5, Karen Exley ${ }^{5}$, Alec Dobney ${ }^{2}$, lain Lake ${ }^{3}$ and Alex Elliot ${ }^{1,4}$ \\ ${ }^{1}$ Real-time Syndromic Surveillance Team, Public Health England, Birmingham, United Kingdom; ${ }^{2}$ Public Health England \\ Environmental Hazards and Emergencies Department, Birmingham, United Kingdom; ${ }^{3}$ University of East Anglia, Norwich, United \\ Kingdom; ${ }^{4}$ National Institute for Health Research, Health Protection Research Unit in Emergency Preparedness and Response, \\ London, United Kingdom; ${ }^{5}$ Public Health England Environmental Hazards and Emergencies Department, Chilton, United Kingdom
}

\section{Objective}

To explore the utility of syndromic surveillance systems for detecting and monitoring the impact of air pollution incidents on health-care seeking behaviour in England between 2012 and 2017.

\section{Introduction}

The negative effect of air pollution on human health is well documented illustrating increased risk of respiratory, cardiac and other health conditions. [1] Currently, during air pollution episodes Public Health England (PHE) syndromic surveillance systems [2] provide a near real-time analysis of the health impact of poor air quality. In England, syndromic surveillance has previously been used on an ad hoc basis to monitor health impact; this has usually happened during widespread national air pollution episodes where the air pollution index has reached 'High' or 'Very High' levels on the UK Daily Air Quality Index (DAQI). [3-5]

We now aim to undertake a more systematic approach to understanding the utility of syndromic surveillance for monitoring the health impact of air pollution. This would improve our understanding of the sensitivity and specificity of syndromic surveillance systems for contributing to the public health response to acute air pollution incidents; form a baseline for future interventions; assess whether syndromic surveillance systems provide a useful tool for public health alerting; enable us to explore which pollutants drive changes in health-care seeking behaviour; and add to the knowledge base.

\section{Methods}

The systematic approach will involve accessing historical data for air pollution incidents and syndromic surveillance data over the period 2012-17 across England. We will use $\mathrm{PM}_{10}, \mathrm{PM}_{2.5}$, ozone, $\mathrm{NO}_{2}$, $\mathrm{SO}_{2}$ and DAQI data to define air pollution periods, and historical syndromic surveillance system data for respiratory syndromes (asthma, difficulty breathing, wheeze, cough, bronchitis, sore throat and allergic rhinitis), cardiac (all cardiovascular and myocardial infarction) and eye irritation/conjunctivitis syndromes. We will use regression modelling and cross-correlation analyses to determine the effects of air pollution, weather and pollen upon these syndromes and thus provide evidence of the sensitivity of these systems. Historical data on additional environmental variables including temperature and precipitation, humidity and thunderstorm activity, pollen and fungal spores will be accounted for in the regression models, as well as data on influenza and respiratory syncytial virus (RSV) laboratory reports. We will include sub-national geographies and age/gender analyses in the study depending on the data availability and suitability.

\section{Results}

Initial results presented will include the preliminary descriptive epidemiology with a focus on asthma and the impact of air pollution incidents on health-care seeking behaviour using data from the PHE national syndromic surveillance systems.

\section{Conclusions}

We aim to demonstrate an innovative use of syndromic surveillance data to explore the impact of air pollution incidents on health-care seeking behaviour in England, in turn improving our understanding of the sensitivity and specificity of these systems for detecting the impact of air pollution incidents and to contribute to the knowledge base. This understanding will improve the public health response to future incidents.

\section{Keywords}

Syndromic surveillance; air pollution; time series; asthma

\section{References}

1. World Health Organization (WHO). Preventing disease through healthy environments. Exposure to air pollution: A major public health concern. (http://www.who.int/ipcs/features/air_pollution.pdf). Accessed 28/09/2017

2. Public Health England. Syndromic surveillance: systems and analyses (https://www.gov.uk/government/collections/syndromic-surveillancesystems-and-analyses). Accessed 20/09/2017

3. Department for Environment Food and Rural Affairs (Defra). Daily Air Quality Index (DAQI). (https://uk-air.defra.gov.uk/airpollution/daqi). Accessed 28/06/2017

4. Smith GE, et al. Using real-time syndromic surveillance systems to help explore the acute impact of the air pollution incident of March/ April 2014 in England. Environ Res 2015; 136: 500-504.

5. Elliot AJ, et al. Monitoring the effect of air pollution episodes on health care consultations and ambulance call-outs in England during March/ April 2014: A retrospective observational analysis. Environ Pollut 2016; 214: 903-911.

\section{*Sally Harcourt}

E-mail: sally.harcourt@phe.gov.uk 